\title{
Compliance and knowledge of hypertensive patients attending PHC centres in Al-Khobar, Saudi Arabia
}

\section{L.S. Al-Sowielem ' and A.G. Elzubier'}

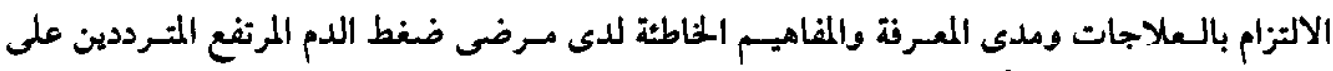

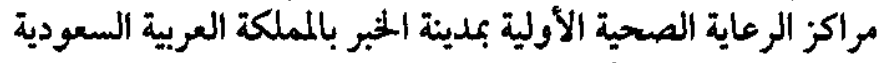

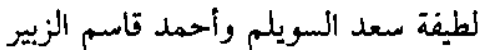

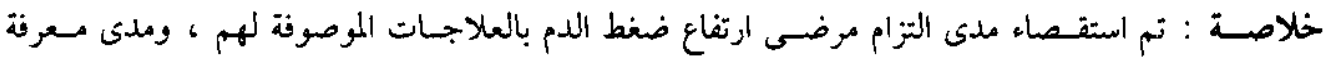

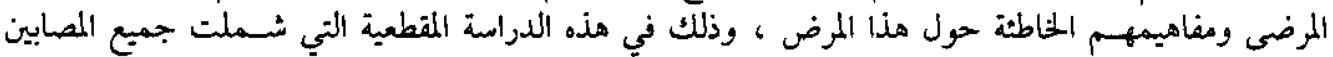

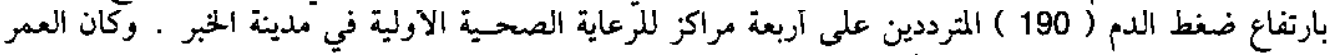

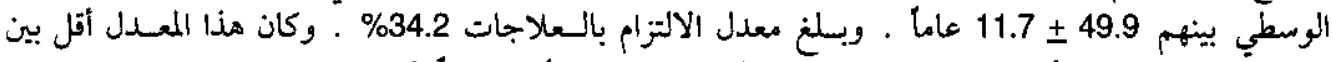

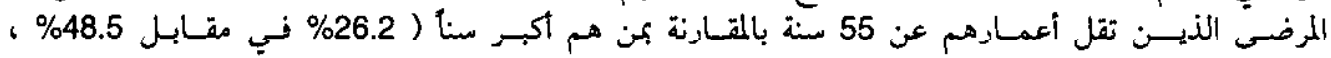

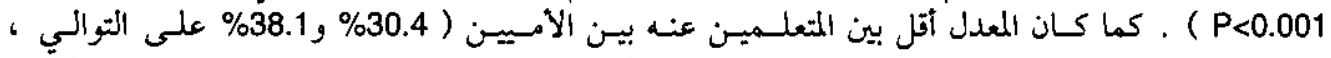

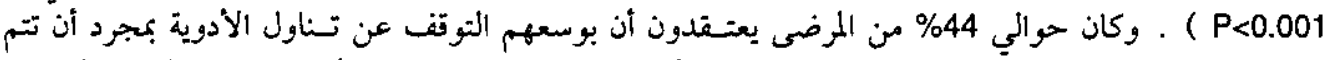

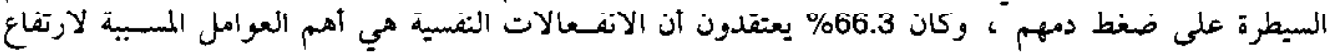

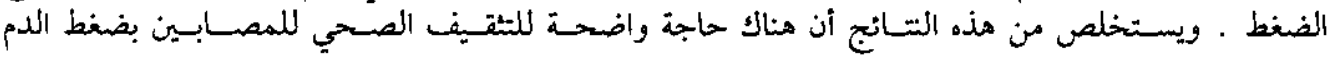
- المذتفع

ABSTRACT The compliance of hypertensive patients and patients' knowledge and misconceptions about hypertension were investigated in a cross-sectional study of all hypertensive patients (190) attending four primary hoalth oaro oentros in Al-Khobar, Saudi Arabia. Tho moan ago wae $40.0=11.7$ yoars. The ovorall compliance rate was $34.2 \%$; the rate was lower in those aged $<55$ years than older patients $(26.2 \%$ versus $48.5 \% ; P<0.001)$. It was also lower among educated than illiterate patients $(30.4 \%$ and $38.1 \%$ respectively; $P<0.001$ ). About $44 \%$ of patients thought that they should stop drug treatment once they achieved blood pressure control and $66.3 \%$ believed that emotional stress was the most important etiological factor in hypertension. The findings indicate that there is a clear need for health education of hypertensive patients.

L'abservance thérapeutique, les connaissances et les idées fausses chez les hypertendus consultant dans les centres de soins de santé primaires à Al-Khobar (Arabie saoudite)

RESUME L'observance du traitement chez les hypertendus et les connaissances et idées fausses des patients en ce qui conceme l'hypertension ont été examinées au cours d'une étude transversale de tous les hypertendus (190) consultant dans quatre centres de soins de sante primaires de la ville d'Al-Khobar. L'áge moyen était de 49,9 ans $\pm 11,7$ ans. Le taux d'observance global était de $34,2 \%$; il était moins élevé chez les patients de moins de 55 ans que chez les patients plus âgés $(26,2 \%$ contre $48,5 \% ; P<0,001)$. Il était aussi moins élevé chez les patients ayant un certain niveau d'instruction que chez les patients analphabètes $(30,4 \%$ et $38,1 \%$ respectivement; $P<0,001)$. Environ $44 \%$ des patients pensaient qu'ils devaient arrêter le traitement une fois ja tension artérielle stabilisée et $66,3 \%$ pensaient que le stress émotionnel était le facteur étiologique le plus important de l'hypertension. Les résultats montrent qu'il existe un besoin manifeste d'éducation sanitaire pour les hypertendus.

' Department of Family and Community Medicine, College of Medicine and Medical Sciences, King Faisal university, Dammam, saudi Arabla.

Received: 22/07/97; accepted: 04/09/97

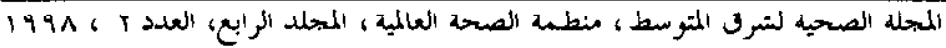




\section{Introduction}

Hypertension is a common disease. Community surveys in industrialized countries have shown a prevalence of $15 \%-38 \%$ in people aged $\geq 30$ years $[1-3]$. The disease continues to be a leading cause of morbidity and mortality from coronary artery disease and stroke $[4,5]$. Studies carried out in Saudi Arabia have revealed a prevalence of hypertension of about $10 \%[6,7]$. Significant progress has been made in the drug treatment of hypertension [8,9]. Achieving and monitoring control of the disease is a problem that is shared by the patients and their physicians. An important issue in failure to control hypertension is low compliance with treatment, which remains a universal problem [10-12]. Compliance involves not only taking the prescribed medications but also adherence to follow-up appointments and maintaining the recommended lifestyle modifications. Furthermore, the patient should be an active participant in the plan of care. Patients' knowledge of hypertension and its complications is an important factor in achieving better compliance, and hence control. A study carried out in Al-Khobar showed a considerable lack of knowledge among patients with hypertension attending the cardiology and nephrology units in a teaching hospital [13].

The objective of this study was to assess the compliance of hypertensive patients and their knowledge and misconceptions about their disease in a primary health care setting.

\section{Subjects and methods}

This cross-sectional study was carried out in Al-Khobar, Eastern Province, Saudi Arabia. Four primary health care centres were randomly selected from a total of $10 \mathrm{cen}$ - tres serving the city's population. All patients who had essential hypertension, for at least one year, and who were registered in those selected centres, were included in the study. Patients were interviewed by trained interviewers using a structured questionnaire. The data obtained comprised age, sex, nationality, marital status, educational level, positive family history of hypertension, smoking status. the presence of other chronic diseases, duration of hypertension, mode of diagnosis of hypertension (whether accidentally or by symptoms), number of drugs taken for hypertension, regularity of taking the drugs, the presence of difficulties in complying with treatment, regularity of follow-up, and whether the patient was seen by the same doctor at each follow-up visit. Patients were also asked their opinion on the possibility of a total cure for hypertension and whether treatment should be stopped if blood pressure were controlled. In addition, the patients' opinions on age and gender susceptibility, causes and complications of hypertension, and if it was possible to prevent the disease were sought.

Weight, height and blood pressure were recorded during the visit. Body mass index (BMI) was calculated as weight in kilograms divided by the square of height in metres. A BMI of $\geq 27.8 \mathrm{~kg} / \mathrm{m}^{2}$ for men and $\geq 27.3 \mathrm{~kg} /$ $\mathrm{m}^{2}$ for women was considered high. Compliance was measured by two methods. The first was the therapeutic outcome method where diastolic blood pressure (DBP) of $<$ $90 \mathrm{mmHg}$ was considered indicative of compliance with treatment [14]. The second was the self-reporting method.

Data were assessed using Epi-Info. Frequency distributions were generated. Means were expressed as mean \pm 1 standard deviation. The chi-squared $\left(\chi^{2}\right)$ test was used to assess the possible differences between categories. $P<0.05$ was considered significant. 


\section{Results}

\section{Sample characteristics}

The sample was composed of 139 females and 51 males who satisfied the criteria for inclusion in the study. The overall mean age was $49.9 \pm 11.7$ years. Saudi nationals constituted $72.6 \%$ of the sample. The overall mean BMI was $30.04 \pm 5.64 ; 27.6 \pm 3.98$ for males and $30.8 \pm 5.96$ for females. The overall mean DBP was $89.5 \pm 9.92 \mathrm{mmHg}$ and the mean duration of hypertension was $7.03 \pm 6.23$ years. Diagnosis of hypertension was made accidentally in $83(43.7 \%)$ of the patients, while the rest were diagnosed when presenting with symptoms of hypertension or its complications. A positive family history of hypertension was found in $94(49.5 \%)$ of the patients. Some $58.9 \%$ had other chronic diseases, such as diabetes mellitus, ischaemic heart disease and osteoarthritis, and $78.9 \%$ were managed on one antihypertensive drug, while the rest were using two or more drugs.
Cigarette smoking was prevalent in $7.9 \%$ of the patients.

\section{Compliance rate}

When assessed according to the therapeutic outcome (DBP method), 65 parients $(34.2 \%)$ were found to be compliant. On the other hand, the self-reporting method revealed that $142(74.7 \%)$ were compliant. With the therapeutic outcome method, the compliance rate was significantly higher among illiterate patients than educated ones, and among patients over 55 years of age than those who were younger. There was no significant difference in compliance rates between males and females, nor between Saudis and non-Saudis (Table 1).

Patients who were regular on follow-up $(82.1 \%)$ had a significantly higher compliance rate than those who were irregular $(37.8 \%$ and $17.6 \%$ respectively; $P<0.02$ ). The presence or absence of difficulty with compliance, availability of continuity of care, preference for place of care, number

\begin{tabular}{|c|c|c|c|c|}
\hline \multirow{3}{*}{$\begin{array}{l}\text { Variable } \\
\text { Sex }\end{array}$} & \multirow[t]{3}{*}{ Total } & \multicolumn{2}{|c|}{ Compliance } & \multirow[t]{2}{*}{ Significance } \\
\hline & & & & \\
\hline & & & & \\
\hline Male & 51 & 16 & 31.4 & NS \\
\hline Female & 139 & 49 & 35.3 & \\
\hline \multicolumn{5}{|l|}{ Age (years) } \\
\hline$<55$ & 122 & 32 & 26.2 & \\
\hline $55-64$ & 42 & 20 & 47.6 & $<0.002$ \\
\hline$\geq 65$ & 26 & 13 & 50.0 & $\left(x^{2}=9.65\right)$ \\
\hline \multicolumn{5}{|l|}{ Nationality } \\
\hline Saudi & 138 & 46 & 34.1 & NS \\
\hline Non-Saudi & 52 & 16 & 34.6 & \\
\hline \multicolumn{5}{|l|}{ Educational level } \\
\hline Illiterate & 98 & 37 & 37.7 & NS \\
\hline Any education & 92 & 28 & 30.4 & \\
\hline
\end{tabular}

$N S=$ not significant 


\begin{tabular}{|c|c|c|c|c|}
\hline \multirow[t]{2}{*}{ Varlable } & \multirow[t]{2}{*}{ Total } & \multicolumn{2}{|c|}{ Compliance } & \multirow[t]{2}{*}{ Significance } \\
\hline & & & & \\
\hline \multicolumn{5}{|c|}{ Difficulty with compliance } \\
\hline Present & 36 & 13 & 36.1 & NS \\
\hline Not present & 154 & 52 & 33.8 & \\
\hline \multicolumn{5}{|l|}{ Follow-up } \\
\hline Regular & 156 & 59 & 37.8 & $<0.02$ \\
\hline Not regular & 34 & 6 & 17.6 & $\left(\chi^{2}=5.05\right)$ \\
\hline \multicolumn{5}{|l|}{ Continuity of care } \\
\hline Present & 92 & 34 & 36.9 & NS \\
\hline Not present & 98 & 31 & 31.6 & \\
\hline \multicolumn{5}{|c|}{ Preference for place of care } \\
\hline PHC centre & 77 & 28 & 36.4 & NS \\
\hline Hospital & 29 & 8 & 27.6 & \\
\hline \multicolumn{5}{|l|}{ Number of drugs } \\
\hline One & 150 & 55 & 36.7 & NS \\
\hline Two or more & 40 & 10 & 25.0 & \\
\hline \multicolumn{5}{|l|}{ Mode of presentation } \\
\hline With symptoms & 107 & 36 & 33.6 & NS \\
\hline Accidental finding & 83 & 29 & 34.9 & \\
\hline \multicolumn{5}{|c|}{ Other chronic diseases } \\
\hline Present & 112 & 43 & 38.4 & NS \\
\hline Not present & 78 & 22 & 28.2 & \\
\hline
\end{tabular}

NS = not significant

of drugs taken for hypertension, mode of diagnosis of hypertension and presence or absence of other chronic diseases did not significantly affect the compliance rate (Table 2).

\section{Knowledge of patients about hypertension}

Less than half $(41.6 \%)$ of the patients thought that hypertension could have a permanent cure and $43.7 \%$ that medications could be stopped once control was achieved. As regards susceptibility to hypertension, $40.0 \%$ of patients thought that females were more susceptible than males and $56.3 \%$ thought that elderly people were more likely to suffer from the disease than younger ones (Table 3 ).

Almost two-thirds of the patients (66.3\%) thought that the main etiological factor for hypertension was emotional stress, while only $1.6 \%$ acknowledged the role of heredity in causing the disease. About one-third of the patients ( $31.6 \%$ ) did not know the complications of hypertension, while $42.1 \%$ knew that it might lead to neurological complications and $1.6 \%$ were aware that the disease might lead to renal complications (Table 3 ). 
Table 3 Knowledge of hypertensive patients $(n=190)$ about disease aspects

\begin{tabular}{|c|c|c|}
\hline Disease aspect & No. & $\%$ \\
\hline \multicolumn{3}{|l|}{ Can hypertension be cured? } \\
\hline Yes & 79 & 41.6 \\
\hline No & 111 & 58.4 \\
\hline \multicolumn{3}{|l|}{$\begin{array}{l}\text { Can drugs be stopped once } \\
\text { control is achieved? }\end{array}$} \\
\hline Yes & 83 & 43.7 \\
\hline No & 107 & 56.3 \\
\hline \multicolumn{3}{|c|}{$\begin{array}{l}\text { Which sex is more susceptible } \\
\text { to hypertension? }\end{array}$} \\
\hline Males & 37 & 19.5 \\
\hline Females & 76 & 40.0 \\
\hline Both males and females & 71 & 37.4 \\
\hline Don't know & 6 & 3.2 \\
\hline \multicolumn{3}{|l|}{$\begin{array}{l}\text { Which age groups are more } \\
\text { susceptible? }\end{array}$} \\
\hline Elderly persons & 107 & 56.3 \\
\hline Middlo-agod persons & 37 & 10.6 \\
\hline Young persons & 1 & 0.5 \\
\hline All ages equally susceptible & 45 & 23.7 \\
\hline \multicolumn{3}{|l|}{ What causes hypertension? } \\
\hline Emotional stress & 126 & 66.3 \\
\hline Obesity & 19 & 10.0 \\
\hline $\begin{array}{l}\text { Excessive salt intake } \\
\text { Heredity }\end{array}$ & $\begin{array}{r}18 \\
3\end{array}$ & $\begin{array}{l}9.5 \\
1.6\end{array}$ \\
\hline Don't know & 24 & 12.6 \\
\hline \multicolumn{3}{|l|}{$\begin{array}{l}\text { What are the complications } \\
\text { of hypertension? }\end{array}$} \\
\hline Neurological & 80 & 42.1 \\
\hline Cardiovascular & 47 & 24.7 \\
\hline Renal & 3 & 1.6 \\
\hline Don't know & 60 & 31.6 \\
\hline
\end{tabular}

\section{Discussion}

The concept of management of hypertension in primary health care centres is strongly justified and widely practised [15-18]. Our study explored the state of care of hypertensive patients in primary health care, especially when considered in light of patients' compliance with treatment and their knowledge of the disease and its treatment.

The patients studied were predominantly middle-aged hypertensive women, with a fairly high rate of positive family history of hypertension, who were overweight and had a low compliance rate. The last two features and the opinions of the patients reflect poor management of the disease among the sample studied.

The compliance rate in our study is low compared with earlier findings in labuk, Saudi Arabia [19], although there are differences in the methods used. Our data did not show a significant variation of compliance with sex, nor with nationality, but relatively young patients had a lower compliance rate than older ones. This probably reflects the traditional emphasis on family care for the elderly in the community. This finding is similar to that of earlier studies [20]. We are aware that more accurate estimations of compliance are currently being achieved by newer methods [2I].

We also explored factors associated with patients' attitudes and behaviour towards care for hypertension, such as regularity of follow-up, continuity of care with one physician and preference for place of care. The results clearly reveal the importance of regular follow-up in achieving better compliance, emphasizing the need for health education to enforce this habit. The recent practice of monotherapy for hypertension was prevalent in this study although it did not have a significant impact on the compliance rate.

The relationship between patient misconceptions about the disease and poor compliance has been documented [22]. In this regard, our results revealed that a considerable proportion of the patients had misconceptions about the treatment of hypertension, such as believing in a permanent cure for essential hypertension and discontinuation of drugs once control is 
achieved. Since these misconceptions have a considerable impact on compliance, it is imperative that primary health carc physicians correct them through health education. Screening for hypertension will undoubtedly be affected if there are misconceptions such as those related to age and gender susceptibility, as observed in this study. Furthermore, many patients believe that emotional stress is an important etiological factor for hyper- tension and are ignorant of other contributing factors which can be corrected, such as excessive salt intake and obesity. Although the frequency of positive family history of hypertension was high (49\%) among the sample, only $2 \%$ of patients were aware of the role of heredity in the etiology of the disease. These findings emphasize the important role of primary health care pliysicians in educating patients about hypertension.

\section{References}

1. Burt VL et al. Prevalence of hypertension in the US adult population. Results from the Third National Health and Nutrition Examınation Survey, 1988-1991. Hypenension, 1995, 25(3):305-13.

2. Imai $Y$ et al. Ambulatory blood pressure monitoring in evaluating the prevalence of hypertension in adults in Ohasama, a rural Japanese community. Hypertension research, 1996, 19(3):207-12.

3. Tormo MJ et al. Prevalence and control of arterial hypertension in the south-east of Spain: a radical but still insufficient improvement. European joumal of epidemiotogy, 1997, 13(3):301-8.

4. Tverdal A. Systolic and diastolic blood pressures as predictors of coronary heart disease in middle-aged Norwegian men. British medical journal, 1987, 294:671-3.

5. Selmer R. Blood pressure and twentyyear mortality in the city of Bergen, Norway. American journal of epidemiology, 1992, 146(4):428-40.

6. Ahmed AF, Mahmoud ME. The prevalence of hypertension in Saudi Arabia. Saudi medical journal, 1992, 6:548-51.

7. Aboltotoun MA et al. Prevalence of hypertension in south-western Saudi Arabia.
Eastern Mediterranean health journal, 1996, 2(2):211-8.

8. Collins $\mathrm{R}$ et al. Epideminlogy, blood pressure, stroke and coronary heart disease. II. Short-term reduction in blood pressure: overview of randomised drug trials in their epidemiological context. Lancet, 1990, 335:827-38.

9 Neaton JD et al Treatment of mild hypertension study. Final results. Journal of the American Medical Association, 1993, 270:713-24.

10. Clark LT. Improving compliance and increasing control of hypertension: needs of special hypertensive populations. American heart journal, 1991, 121:664-9.

11. Sharkness CM, Snow DA. The patient's view of hypertension and compliance. American journal of preventive medicine, 1992, 8:141-6.

12. Richardson MA, Simons-Morton B, Annegers JF. Effect of perceived barriers on compliance with antihypertensive medication. Health education quarterly, 1993, 20:489-503.

13. Al-Khadra A, Al-Muhana F, Ibrahim I. Patients' knowledge of hypertension and its management. Joumal of the Saudi Heart Association, 1991, 3(3):106-9. 
14. Fletcher SW et al. Predicting blood pressure control in hypertensive patients: an approach to quality-of-care assessment. Medical care, 1979, 17(3):285-92.

15. Hosie J, Wikhund I. Managing hypertension in general practice: can we do better? Journal of human hypertension, 1995, 9(suppl. 2): $\$ 15-8$.

16. Goldstein $A O$ et al. Variations in hypertension control in indigent rural primary care clinics in North Carolina. Archives of family medicine, 1994, 3(6):514-9.

17. Aubin $\mathrm{M}$ et al. Control of arterial hypertension: effectiveness of an intervention performed by family practitioners. Canadian family physician, 1994, 40:1742-52.

18. Muhlhauser 1 et al. Evaluation of a struotured treatment and teaching programme on hypertension in general practice. Clinical and experimental hypertension, 1993, 15(1):125-42.

19. Khalil SA, Elzubier AG. Drug compilance among hypertensive patients in Tabuk City, Saudi Arabia. Journal of hypertension, 1997, 15:561-5.

20. Marilyn R. Factors associated with adherence in hypertensive patients. Annals of medicine, 1987, 14(4):245-8.

21. Mallion JM et al. Use of a microprocessor-equipped tablet box in monitoring compliance with antihypertensive treatment. Joumal of cardiovascular pharmacology, 1992, 19(suppl. 2):S41-8.

22. Heurtin RS, Reisin E. The relation of culturally influenced lay models of hypertonsion to compliance with treatment. American journal of hypertension, 1992, 5(11):787-92. 